\section{Mujer joven, hija de padre con síndrome de Alport, debuta con síndrome nefrótico impuro}

\author{
FERNANDO GONZÁLEZ ${ }^{1}$, GONZALO MÉNDEZ ${ }^{2}$, \\ DANIELA NAVARRETE ${ }^{3}$
}

Editor Invitado: DR. EMILIO ROESSLER B. ${ }^{1}$

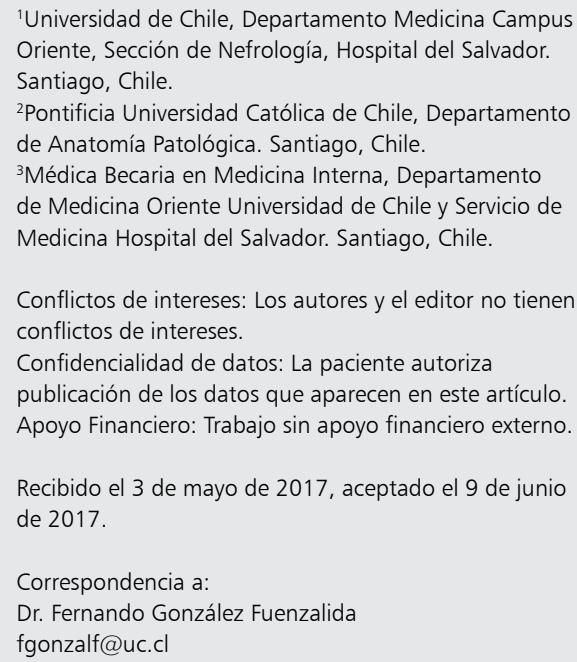
Oriente, Sección de Nefrología, Hospital del Salvador. Santiago, Chile.

2Pontificia Universidad Católica de Chile, Departamento de Anatomía Patológica. Santiago, Chile.

${ }^{3}$ Médica Becaria en Medicina Interna, Departamento de Medicina Oriente Universidad de Chile y Servicio de Medicina Hospital del Salvador. Santiago, Chile.

Conflictos de intereses: Los autores y el editor no tienen conflictos de intereses.

Confidencialidad de datos: La paciente autoriza publicación de los datos que aparecen en este artículo. Apoyo Financiero: Trabajo sin apoyo financiero externo.

Recibido el 3 de mayo de 2017, aceptado el 9 de junio de 2017.

Correspondencia a:

Dr. Fernando González Fuenzalida fgonzalf@uc.cl

M ujer de 19 años, previamente sana. Antecedentes familiares de Enfermedad de Alport en padre, abuela, tío y primo paternos, dos de ellos trasplantados renales por esta causa. Desde un mes antes de su consulta presenta compromiso del estado general, astenia, anorexia, edema progresivo de extremidades inferiores asociado a orina espumosa y oscuras, color "Coca-Cola". Una semana antes de su ingreso se agregó edema facial matinal de predominio palpebral. No refiere infección previa a estos síntomas, uso de medicamentos, ni historia de artralgias, mialgias o compromiso de piel.

\section{Examen físico}

Lúcida, pálida, con edemas palpebral, pretibial y bimaleolar. No se vieron lesiones cutáneas. Presión arterial 130/80 $\mathrm{mmHg}$, pulso $64 \mathrm{x}$ min regular, afebril. Resto del examen normal.

\section{Laboratorio de ingreso}

$\mathrm{Hb} 8,6 \mathrm{~g} / \mathrm{dL}$, normocitosis y normocromía. Leucocitos $2.500 \mathrm{x} \mathrm{mm}^{3}$, neutrófilos $1.528 \mathrm{y}$ plaquetas $163.000 \times \mathrm{mm}^{3}$, Nitrógeno Ureico $31 \mathrm{y}$ Creatinina $1,6 \mathrm{mg} / \mathrm{dL}$, electrolitos normales, orina: proteínas $500 \mathrm{mg} / \mathrm{dL}$ Sedimento con leucocitos 75/uL e incontables hematíes más cuerpos ovales grasos en regular cantidad. Urocultivo negativo.
Dr. González: Con estos datos, ¿qué síndrome nefrológico presenta esta enferma y porqué?

- El cuadro clínico sugiere de una enfermedad glomerular: Edema progresivo de cara y extremidades asociado a orina espumosa y de color "Coca-Cola". La presión arterial, de 130/80 $\mathrm{mmHg}$, parece ser normal; sin embargo, lo habitual para una mujer de 19 años es que su presión sistólica sea inferior a $120 \mathrm{mmHg}$. Una presión sistólica elevada, sugiere, en una persona joven, una expansión del volumen extracelular, lo que es compatible con el edema de la historia y del examen físico. Siendo así, esta paciente parece tener un síndrome nefrítico ${ }^{1,2}$.

- Laboratorio: El examen de orina evidencia una alteración de la barrera de filtración (proteinuria $500 \mathrm{mg} / \mathrm{dL}$ y cuerpos ovales grasos), y existe, además, elementos que sugieren inflamación glomerular (hematuria, aun cuando no se especifica si los eritrocitos son dismórficos) e inflamación intersticial (leucocituria).

- La reducción de la velocidad de filtración glomerular (creatinina elevada) puede ser consecuencia de la enfermedad glomerular, intersticial o ambas.

- Analizando el laboratorio en conjunto con el cuadro clínico, puede plantearse un síndrome nefrítico con proteinuria nefrótica o un síndrome nefrótico impuro (hematuria e hiper- 
tensión arterial), amén de una posible nefritis intersticial, además de una insuficiencia renal, probablemente de inicio reciente (un mes de evolución).

Dr. González: Dado los antecedentes familiares una Enfermedad de Alport, ¿consideraría Ud. ese diagnóstico como primera posibilidad diagnóstica?

- La enfermedad de Alport es una condición hereditaria heterogénea que puede tener tres formas de transmisión: ligada al cromosoma X (80\%), forma autosómica dominante $(<1 \%)$ o autosómica recesiva (20\%).

- Pareciera que la abuela es la primera persona de la familia con esta patología y que ella la transmitió a su descendencia de una forma ligada al cromosoma X (padre, tío y primo de la paciente).

- Aunque no puede descartarse que se trate de una forma autosómica dominante del síndrome de Alport, dado que no se menciona si existe familiares cercanos a la pacientes que sean sanos desde el punto de vista nefrológico, esta variante es muy rara. La forma autosómica recesiva no es compatible con la descripción clínica del árbol familiar.

- La enfermedad de Alport, en mujeres jóvenes, se suele caracterizar sólo por un examen de orina con microhematuria, siendo la proteinuria y reducción de la velocidad de filtración glomerular inhabituales ${ }^{3}$.

- Por todo lo anterior, considero que la enfermedad de Alport no explica el cuadro clínico de esta paciente, aunque no se puede descartar que, de realizarse una biopsia renal, se encuentren alteraciones morfológicas en las membranas basales glomerulares (delaminación) o, si se realizara una análisis genético, se pudiera demostrar anormalidades en los genes $\alpha 3, \alpha 4$ o $\alpha 5$ del colágeno tipo 4. En estas dos eventualidades, se debería plantear la coexistencia simultánea de dos enfermedades renales ${ }^{3}$.

Dr. González: ¿Qué diagnósticos probables plantearía y que exámenes adicionales solicitaría para confirmarlos o excluirlos?

- En resumen, el cuadro clínico y de laboratorio muestran una enfermedad con elementos inflamatorios glomerulares (nefritis), anormalidades funcionales en la barrera de filtración (nefrosis) y nefritis intersticial. Esta coexistencia de anormalidades no es frecuente, salvo en lupus eritematoso y, raramente, en infecciones (Virus inmuno deficiencia humana, Hepatitis C, influenza), crioglobulinemia, síndrome de Sjögren, enfermedad asociada a IgG4, Granulomatosis con poliangeitis (antiguamente llamada Granulomatosis de Wegener) o uso de algunas drogas (interferones, bifosfonatos, antiinflamatorios no esteroidales, antiplaquetarios).

- De ellas, la más probable es el lupus eritematoso sistémico. Además, la paciente es una mujer joven y en el laboratorio destacan anemia, leucopenia y linfopenia.

- En este momento, solicitaría:

- Proteínemia total y albuminemia, colesterol total y proteinuria cuantitativa para establecer el diagnóstico de síndrome nefrótico.

- Anti VIH, Anti VHC y Antígeno de superficie de hepatitis B (HBsAg) para descartar esas infecciones.

- Anticuerpos anti nucleares (ANA), Anticuerpo anti DNA nativo (DNAn) y fracciones 3 y 4 del complemento (C3 y C4) para diagnosticar lupus eritematoso.

- Factor reumatoide para aumentar la sospecha de crioglobulinemia.

- Cuantificación de inmunoglobulinas para aumentar la sospecha de enfermedad asociada IgG4.

- Test de Coombs para descartar una anemia hemolítica.

- Es muy probable se requiera de una biopsia renal.

El estudio adicional mostró: proteinuria 9,7 g/24 h, en sangre proteínas 3,6 y Albúmina $1,7 \mathrm{~g} / \mathrm{dL}$, colesterol total 247 , colesterol de alta densidad (HDL) 31, colesterol de baja densidad (LDL) 169 y triglicéridos $230 \mathrm{mg} / \mathrm{dL}$. ANA (+) 1/160 patrón moteado, Ac anti-DNAn $(+)$ $1 / 160 \mathrm{C}_{3}: 24$ y C $_{4} 4 \mathrm{mg} / \mathrm{dL}$. Anticoagulantes lúpicos negativos, $\beta 2$ glicoproteina 1 negativa. AgHBs, Anti VHC y Anti VIH negativos. Electroforesis hipoalbuminemia sin espiga monoclonal.

Dr. González: ¿Cómo interpretaría estos resultados $y$ de ellos, cuál o cuáles es o son los más específicos para apoyar su diagnóstico y, éstos, de qué proceso fisiopatológico están dando cuenta? 
- Los nuevos exámenes permiten diagnosticar un síndrome nefrótico severo (albuminemia $<2,0 \mathrm{~g} / \mathrm{dL}$ ) y un lupus eritematoso sistémico (ANA, Anti DNAn, C3 y C4 y alteraciones hematológicas).

- La fisiopatología planteable es: Existe una enfermedad autoinmune sistémica humoral (ANA, ADNA) con formación de complejos inmunes que consumen complemento ( $\mathrm{C} 3 \mathrm{y}$ $\mathrm{C} 4$ reducidos) y se depositan en el mesangio, subendotelio, subepitelio, o todos, y que explican los elementos nefríticos y nefróticos, respectivamente, además de la caída de la velocidad de filtración glomerular. Adicionalmente, deben coexistir complejos inmunes o una respuesta autoinmune celular contra antígenos tubulares que explicarían los elementos de nefritis intersticial de esta enferma.

- No existe elementos clínicos actuales que permitan sospechar una anemia hemolítica microangiopática (esquistocitos y trombocitopenia) y el anticoagulante lúpico y la $\beta 2$ glicoproteina-1 son negativos.

- La paciente, seguramente, padece de una Glomerulonefritis lúpica proliferativa difusa $y$, muy probablemente, también de una nefritis intersticial.

Dr. González: Para el manejo de esta enferma, ¿consideraría tener el resultado de una biopsia renal o, los datos clínicos son suficientes para toma de decisiones?

- El diagnóstico de esta paciente es claro y el tratamiento, también. Requiere de terapia antiinflamatoria e inmunosupresora potentes y de manera urgente. Por esto, algunos especialistas no realizan una biopsia renal y consideran que la información derivada de ella no justifica el riesgo ni el costo de llevarla a cabo.

- Sin embargo, el análisis histopatológico de la biopsia renal permitirá entender a cabalidad el síndrome nefrológico que padece la paciente, es decir, si los complejos inmunes se localizan más en el espacio subendotelial, que activan más el complemento y reducen más la filtración glomerular o si están en el mesangio o el espacio subepitelial, que suelen ser menos generadores de daño local. También permitirá aquilatar el rol de la nefritis intersticial y cuantificar, aunque sea parcialmente, cuánto daño agudo y reversible (Índice de
Actividad) y cuánto daño crónico e irreversible (Îndice de Cronicidad) coexisten y, con ello, establecer más certeramente el pronóstico de recuperación funcional e histopatológico de la glomerulonefritis.

- El riesgo de la biopsia renal en manos expertas es muy bajo y su costo justifica plenamente la información que entrega.

Se realiza biopsia renal guiada por ecoscopía. $\mathrm{Su}$ resultado fue el siguiente:

Microscopía óptica (Figura 1): contuvo 10 glomérulos, ninguno obsoleto. Todos los glomérulos tenían acentuación de su lobulación con hipercelularidad mesangial y endocapilar difusas, lo que incluía infiltración por células mononucleares y polimorfonucleares neutrófilos. Presentaban de manera segmentaria, asas en alambre, trombos hialinos y cariorrexis. Siete de los glomérulos mostraban compromiso simultáneo por crecientes celulares, tanto segmentarias como globales. El intersticio mostró un moderado infiltrado inflamatorio linfo-histiocitario. La atrofia tubular era leve. Las arterias y arteriolas tenían esclerosis leve.

Microscopía de inmunofluorescencia (Figura 2): contuvo 8 glomérulos, ninguno obsoleto. Se encontró reactividad granular gruesa en mesangio y capilares periféricos, para IgG (4+), IgA (4+), C3 (3 a 4+) y C1q (2+), con leve dominancia de cadenas livianas lambda (4+) sobre kappa (2 a 3+). Se observó también reactividad muy fina para IgG en vasos.

Microscopía de microscopía electrónica (figura 3): contuvo 2 glomérulos, ninguno obsoleto. Ambos presentaban alteración de su arquitectura determinada por hipercelularidad mesangial, presencia de dobles contornos con interposición citoplasmática y depósitos electron densos incorporados en ellos, así como subendoteliales. También se reconocían de manera focal, depósitos densos subepiteliales. Los endotelios contenían numerosas inclusiones túbulo-reticulares. La desaparición pedicelar era completa.

Los hallazgos de la biopsia renal fueron interpretados y concluidos como siguen: 


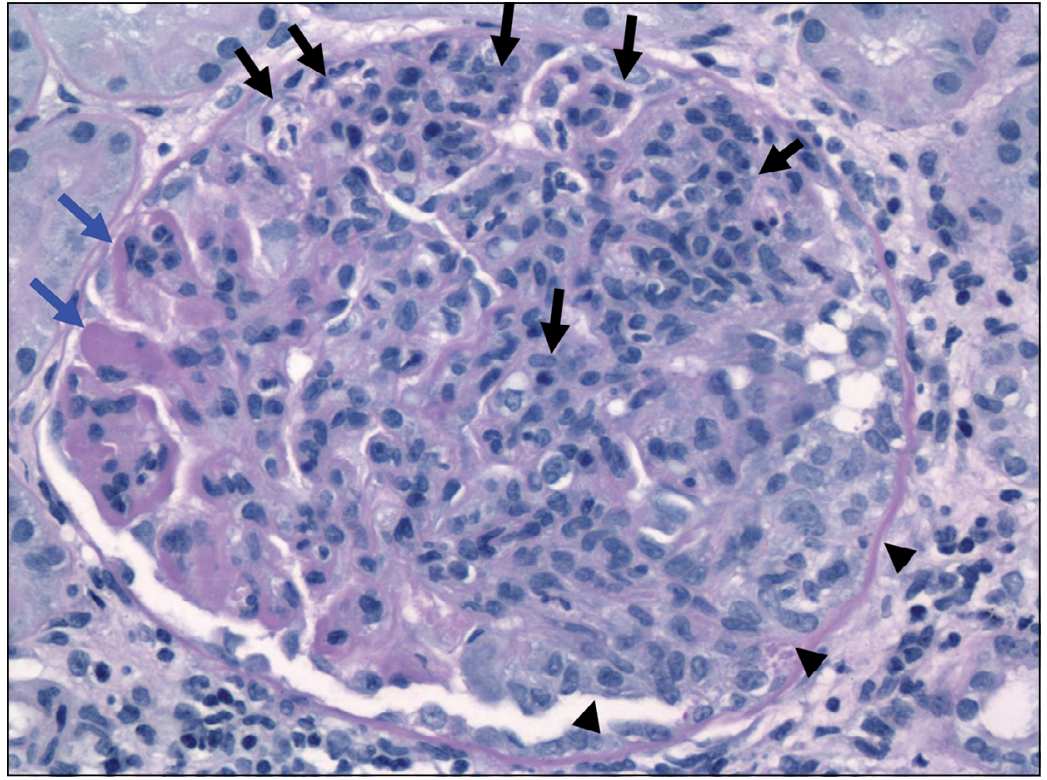

Figura 1. Microscopia óptica. Glomérulo con proliferación endocapilar intensa, mostrando prácticamente todos los lúmenes de capilares ocluidos y rellenos por células inflamatorias mononucleares y polimorfonucleares, las cuales también ocupan los ejes de mesangio (flechas negras). El glomérulo una creciente celular segmentaria (cabezas de flecha). Se reconocen asas en alambre y trombos hialinos (flechas azules) (tinción de PAS, $\mathrm{x} 400)$.

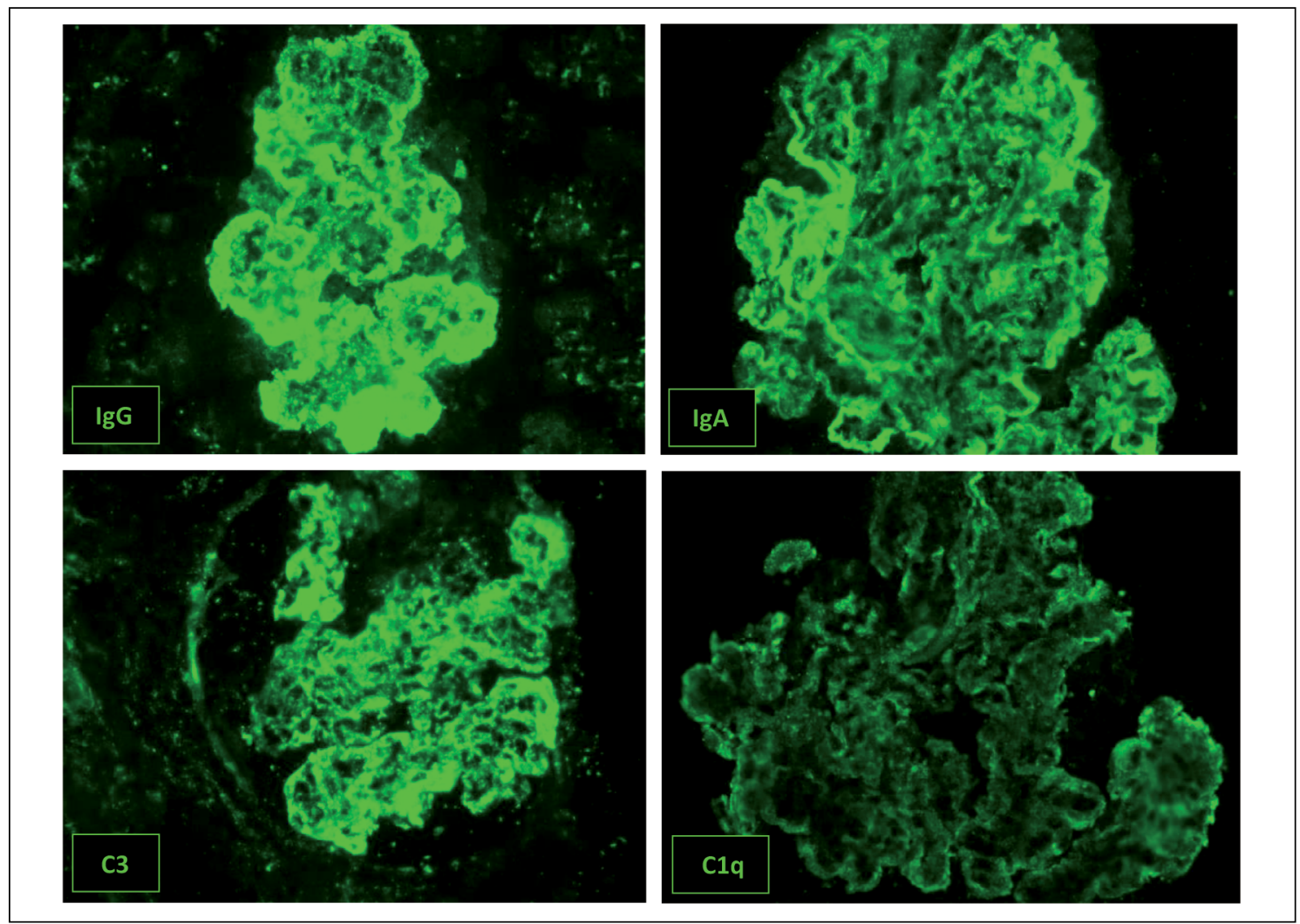

Figura 2. Inmunofluorescencia directa. Se reconocen depósitos granulares gruesos a nivel mesangial y capilar, en éstos últimos, en forma de depósitos confluentes ("comas largas" o "guirnaldas"), dominates para IgG, IgA y C3, con menos intensidad, aunque positivos también, para C1q. (anticuerpos fluoresceinados contra lgG, IgA, C3, C1q; 400x). 


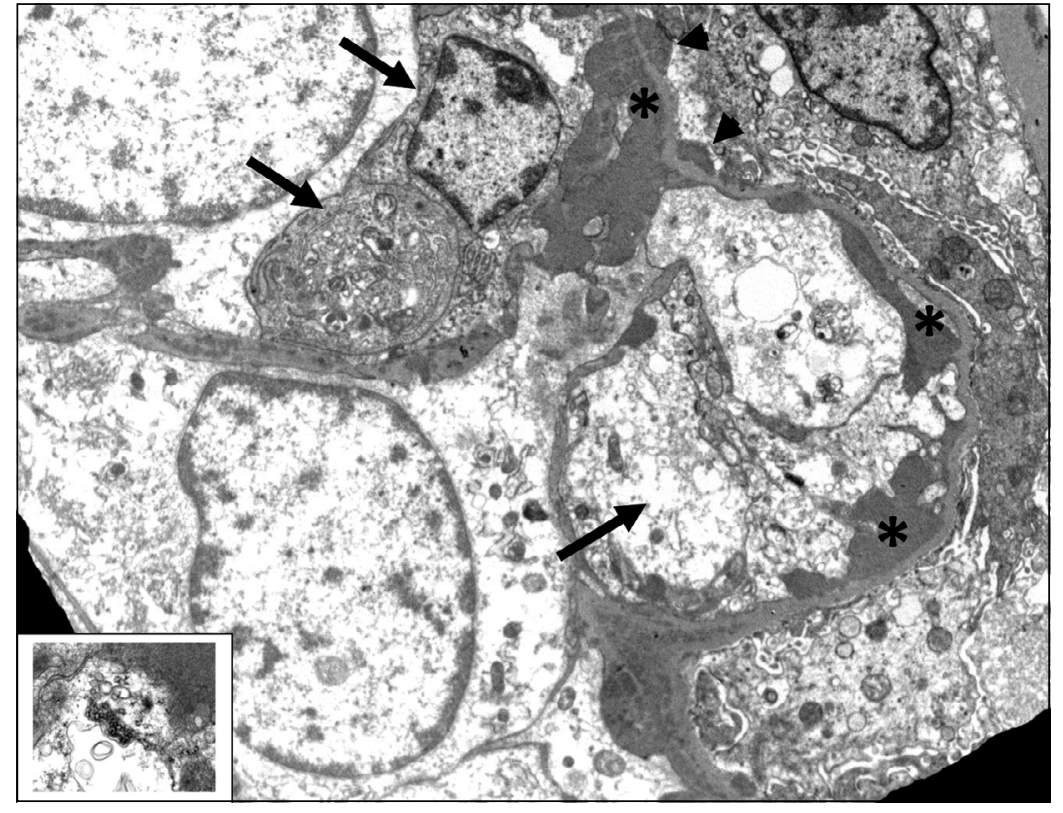

Figura 3. Microscopia electrónica. Segmento de ovillo glomerular que muestra dos asas capilares contiguas sin lumen reconocible y ocupadas por citoplasma de células inflamatorias (flechas). Se reconocen depósitos electron densos subendoteliales confluentes (asteriscos) y algunos subepiteliales (cabezas de flechas). Existe desaparición pedicelar completa (4.200x). Recuadro inferior izquierdo: una inclusión túbulo reticular endotelial. (16.500x). a. Una Glomerulonefritis por complejo inmune con depósitos de IgG e IgA con codominancia variable y depósito secundario de C3-C1q, con patrón proliferativo endocapilar agudo difuso (100\%) y membranoproliferativo temprano, con componente crecéntico celular difuso $(70 \%)$.

b. Evidencia ultraestructural de numerosas inclusiones túbulo-reticulares endoteliales.

c. Nefritis túbulo intersticial linfo-histiocitaria, moderada a acentuada.

La globalidad de estos hallazgos favoreció fuertemente la posibilidad de una nefritis lúpica difusa, global, activa, Clase IV-G (A) de la ISN/ RPS, con un índice de actividad de 21 y un índice de cronicidad de cero.

\section{Dr. González: Con esos datos histológicos, ¿qué opciones terapéuticas existen para esta enferma y cuál elegiría?}

- La interpretación de la biopsia es:

1. Una buena muestra (> 10 glomérulos)

2. No hay glomérulos obsoletos (glomeruloesclerosis) y no hay atrofia tubular ni fibrosis intersticial significativa, lo que sugiere un proceso relativamente reciente y de buen pronóstico de recuperación funcional renal, a pesar de la magnitud de las alteraciones de laboratorio.
3. Se trata de una glomerulonefritis muy agresiva, dado el 70\% de medias lunas (Glomerulonefritis crecéntica por depósito de complejos inmunes o de tipo 2), pero relativamente reciente (medias lunas celulares).

4. Existen algunos elementos de evolución subaguda mediados también por anticuerpos (cambios membrano proliferativos).

5. La patogenia de estas alteraciones es por depósito de complejos inmunes, ya que se identifica IgG, IgA, C3 y C1q en el tejido y el estado inflamatorio se acompaña de niveles elevados de interferón (estructuras túbulo reticulares endoteliales).

6. Existe la nefritis intersticial que se sospechaba. Con la información anterior, además de las alteraciones funcionales renales el tratamiento se debe dirigir a todas las anormalidades observadas en la biopsia ${ }^{4}$ :

a) Inflamación con proliferación endocapilar y extracapilar (medias lunas o crecientes) y nefritis intersticial: Esteroides en dosis altas.

b) Autoinmunidad humoral y celular: Drogas inmunosupresoras.

c) Tratamiento del síndrome nefrótico: Inhibición del eje renina-angiotensina, control de la proteinuria y de la presión arterial, reducción del colesterol y drogas anticoagulantes/antiplaquetarios. 
Se inicia tratamiento con:

- Metilprednisolona: 3 pulsos de 1 g. ev. cada uno.

- Ciclofosfamida un pulsos de 1g. e.v.

- Hidroxicloroquina $200 \mathrm{mg}$ al día. Evoluciona con alza de la presión arterial a valores de 170/90 $\mathrm{mmHg}$ y deterioro progresivo de la función renal alcanzando al séptimo día después del último pulso de metilprednisolona valores de creatinina de $2,9 \mathrm{mg} / \mathrm{dL}$. El internista a cargo de la sala donde está hospitalizada la enferma plantea uso de Rituximab como rescate.

\section{Dr. González: ¿Estaría de acuerdo con uso de} Rituximab en esta paciente dado el deterioro de la función renal observado?

- La paciente evolucionó según lo que pronosticaban los hallazgos histopatológicos. Es decir, deterioro funcional renal (glomerulonefritis rápidamente progresiva) y empeoramiento de la expansión del volumen extracelular (hipertensión arterial y edema).

- El efecto de la terapia instaurada no es inmediato y, en los primeros días de ella (3 o 4 días de iniciada la terapia) lo esperable es observar la historia natural de la glomérulonefritis lúpica difusa severa.

- El disponer de la información histopatológica permite estar tranquilo que, muy probablemente, todo mejorará y que se debe evitar la iatrogenia, como por ejemplo, plantear plasmaféresis, inmunoglobulina humana o Rituximab.

Dr. González: Entonces, ¿para qué situaciones reservaría el uso de Rituximab?

- En el año 2012 se publicó la principal experiencia clínica existente con rituximab, un anticuerpo monoclonal anti-CD20. Los principales resultados fueron que el rituximab, si bien depletó de linfocitos B a quienes sufrían de glomérulonefritis lúpica proliferativa, ello no redundó en un beneficio clínico respecto de placebo para conseguir remisión de la nefropatía ${ }^{5}$.

- La real utilidad del rituximab se desconoce. Sin embargo, pareciere que su uso permitiría "comprar tiempo" para que la terapia inmunosupresora con ciclofosfamida o micofenolato mofetil controle la enfermedad ${ }^{6}$.
Dos semanas después al primer pulso de ciclofosfamida comienza descenso progresivo de creatinina hasta 1,6 mg/dL. Se da de alta protocolo de tratamiento de nefropatía lúpica $\mathrm{NIH}$

\section{Dr. González: ¿Cuáles serían las enseñanzas de este} caso clínico y cuál sería su comentario final?

- La anamnesis y el examen físico cuidadosos permiten diagnosticar certeramente la mayoría de las enfermedades comunes. Sin embargo, para que ello sea cierto, el médico debe meditar cada uno de sus hallazgos e ir armando simultáneamente un árbol de diagnósticos diferenciales compatibles con lo que el paciente entrega.

- El lupus eritematoso es una enfermedad "caprichosa" en sus presentaciones clínicas y siempre debe estar presente en el diagnóstico diferencial de los cuadros polimorfos de las mujeres jóvenes.

- El diagnóstico y el tratamiento de la nefritis lúpica se facilita enormemente con la biopsia renal, ya que permite establecer un diagnóstico preciso, entender su fisiopatología e historia natural, afinar el tratamiento a entregar y establecer un pronóstico de recuperación anatómico y funcional.

- Esta paciente, muy probablemente, recuperará la mayor parte de su función renal y podrá, si se mantiene bajo tratamiento y seguimiento especializados, tener una vida normal.

\section{Referencias}

1. Roessler E. “Síndrome Nefrótico” y "Síndrome Nefrótico” en el Libro Semiología Médica, pág 275 (S. Nefrítico) y pág 278 (S. Nefrótico) Tercera Edición A. Goic A, G. Chamorro y H. Reyes Editores, Editorial Mediterráneo, Santiago Chile 2010.

2. "Expert Panel on Integrated Guidelines for Cardiovascular Health and Risk Reduction in Children and Adolescents: Summary Report". http://www.nhlbi.nih.gov/ health-pro/guidelines/current/cardiovascular-health-pediatric-guidelines/summary\#chap8. Acceso 24/06/2016

3. Clifford EK. Alport and Other Familial Glomerular Syndromes. P 9.51.1-9.51.10. R. Johnson, J. Feehally. Comprehensive Clinical Nephrology, First Edition, 2000, ISBN 0723431175.

4. González F. "Rol de la Biopsia Renal en el Tratamiento de la Nefritis Lúpica”. Reumatología 2006; 22 (2): 42-7. 
5. Rovin BH, Furie R, Latinis K, Looney RJ, Fervenza FC, Sánchez-Guerrero J, Maciuca R, et al; LUNAR Investigator Group. Efficacy and safety of rituximab in patients with active proliferative lupus nephritis: the Lupus Nephritis Assessment with Rituximab study.Arthritis Rheum 2012; 64 (4): 1215-26. doi: 10.1002/art.34359.
Epub 2012 Jan 9G

6. Appel G, Contreras G, Dooley MA, Ginzler EMD, Isenberg D, Jayne $\mathrm{D}$, et al and the Aspreva Lupus Management Study Group. Mycophenolate Mofetil versus Cyclophosphamide for Induction Treatment of Lupus Nephritis". JASN 2009; 20 (5): 110312. 